\title{
Non-genetic expression of adolescent idiopathic scoliosis: a case report and review of the literature
}

\author{
Joris P. S. Hermus · Lodewijk W. van Rhijn • \\ André van Ooij
}

Received: 30 May 2006/Revised: 29 January 2007/ Accepted: 6 February 2007/Published online: 7 March 2007

(C) Springer-Verlag 2007

\begin{abstract}
Treating children with idiopathic scoliosis can amaze someone at the many different ways in which the deformity can present. Most authors state that genetics stipulates the course of adolescent idiopathic scoliosis. This is mainly based on the high concordance in monozygotic twins. However, there is indication that environmental factors have influences on adolescent idiopathic scoliosis. This is the first report in which a monozygotic twin pair is described concordant for idiopathic scoliosis but with different apical levels, magnitudes and age at detection of scoliosis which stresses the importance of environmental factors.
\end{abstract}

Keywords Idiopathic scoliosis - Monozygotic twins · Environmental

\section{Introduction}

The etiology of adolescent idiopathic scoliosis remains uncertain. Several studies suggest that idiopathic scoliosis is a familial condition that has a multifactorial etiology $[13,25]$. This means that idiopathic scoliosis is a genetic trait modified by environmental factors. Twin studies will diminish the effects of environment and allow an understanding of genetics of adolescent idiopathic scoliosis. The fact that monozygotic twins

J. P. S. Hermus $(\bowtie) \cdot$ L. W. van Rhijn .

A. van Ooij

Department of Orthopaedic Surgery,

University Hospital Maastricht,

P.O. Box 5800, 6202 AZ Maastricht,

The Netherlands

e-mail: jhermu@sort.azm.nl have a significantly higher concordance does indicate that genetic factors are of importance in the etiology of adolescent idiopathic scoliosis [11,13,26]. Twin pairs are classified as concordant, when both of the twins have scoliosis, or discordant when only one has a scoliotic curve $[4,13]$. Concordance does not mean that the severity or pattern of the curves is similar in these twins. Despite the genetic aspects in idiopathic scoliosis, we assume that the development of idiopathic scoliosis is influenced multifactorially, for example, progression of the scoliotic curve can be influenced by conservative treatment.

We describe a monozygotic twin pair with different apical levels, magnitude and age at detection of scoliosis, which stresses the importance of environmental influence [20, 28].

\section{Patients and methods}

Monozygosity is defined as twins having identical DNA fingerprinting and completely similar physical characteristics i.e., color of eyes, hair and skin. Our twin-pair had no other abnormalities of the spine on clinical and radiographic examinations and had the similar physical characteristics.

Monozygosity of our twins was confirmed by DNA fingerprinting in the university hospital of Amsterdam.

\section{Case reports}

\section{Child 1}

The school doctor detected scoliosis in a 9-year-old and referred him to our outpatient clinic. There were no 
reports of pain. During physical examination we saw a right-sided thoracic lateral spine deformity. The Adams forward bend test was positive on the right side. Trunk rotation was $4^{\circ}$ using a scoliometer. Neurological examination showed no abnormalities.

The antero-posterior spine radiograph showed a thoracic scoliosis (Th6-L2) with a Cobb angle of $33^{\circ}$ and the curve apex is Th10. In the sagittal view, a hypokyphosis of $22^{\circ}$ is shown (Fig. 1).

Since then Boston brace treatment was started. In June 2005, the curves were improved to a Cobb angle of $18^{\circ}$ without the brace. Trunk rotation was $7^{\circ}$ using a scoliometer. Until now brace treatment is continued.

\section{Child 2}

Patient 2 is the monozygotic twin brother of patient 1. He was carefully screened on our outpatient clinic. There were no clinical signs of scoliosis during our observation at our outpatient clinic. Examination at the age of 14 years showed a mild right-sided thoracic curve of the spine with no neurological abnormalities. Trunk rotation was seven degrees using a scoliometer. The antero-posterior radiograph showed a thoracic scoliosis (Th5-Th10) with a Cobb angle of $12^{\circ}$ and the curve apex is Th7-8. The sagittal view showed a hypokyphosis of $21^{\circ}$ (Fig. 2). In June 2005, the curve
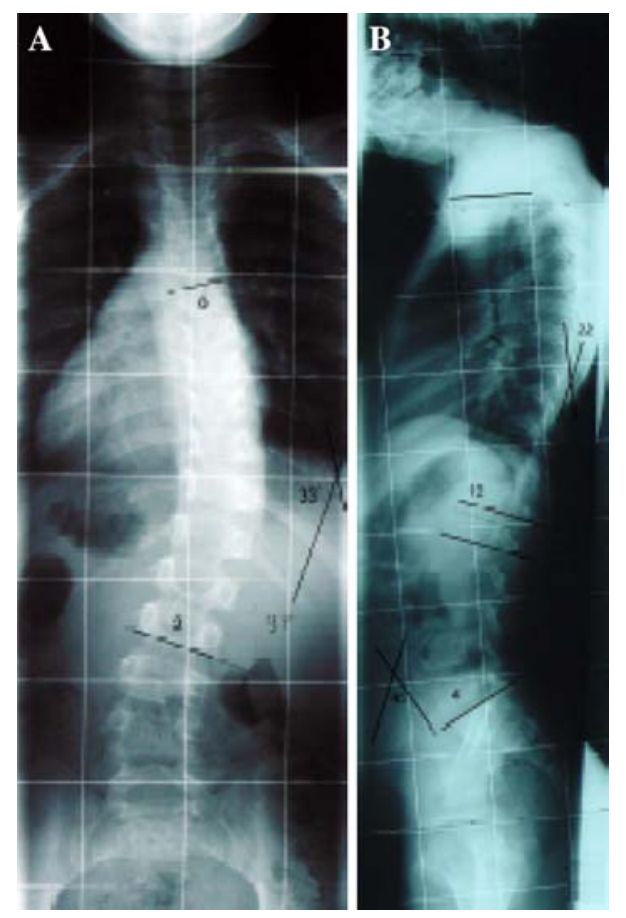

Fig. 1 Child 1 was first seen at the age of 9 years and had a right thoracic scoliosis with a Cobb angle of $33^{\circ}$ (a). On the sagittal plane he had a kyphosis of $22^{\circ}(\mathbf{b})$ progressed to a Cobb angle of $18^{\circ}$. Trunk rotation was $9^{\circ}$ using a scoliometer. He is under observation at our outpatient clinic.

\section{Discussion}

In 1875, Galton stated that monozygotic twins were isogenic, so that any differences in the twins would be related to environmental influences [9]. Monozygosity was defined as twins having completely similar physical characteristics or identical DNA fingerprinting.

Monozygotic twins are more often concordant with adolescent idiopathic scoliosis than dizygotic twins [7, 11, 13, 34]. Kesling and Reinker reported a 73 percent concordance in 37 pairs of monozygotic twins. Most authors regard discordance between monozygotic twins as evidence of an environmental origin [7,9] although, monozygotic twins have been used to demonstrate the influence of environmental factors determining diseases and phenotypes. Phenotypic differences in monozygotic twins could be the result of their epigenetic differences. Epigenetics refers to DNA and chromatin modifications that play a critical role in regulation of various genomic functions. Wong et al. [32] suggest that stochastic events may be a more important cause of phenotypic differences than specific environmental effects. Fraga et al. [8] revealed that the

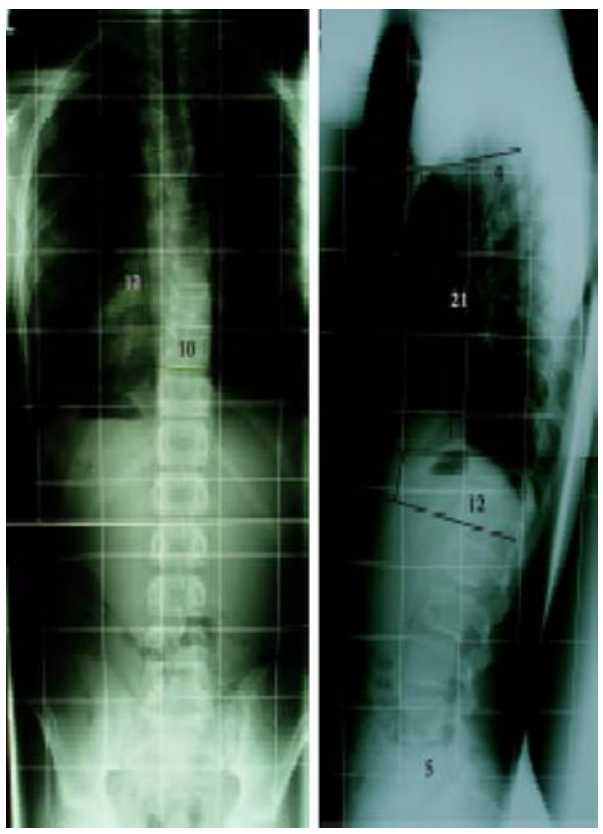

Fig. 2 Child 2 was first seen at the age of 14 years and had a right thoracic scoliosis with a Cobb angle of $12^{\circ}$ (a). On the sagittal plane he had a kyphosis of $21^{\circ}(\mathbf{b})$ 
patterns of epigenetic modifications in monozygotic twin pairs diverge as they become older. The defects in transmitting epigenetic information could accumulate by successive cell divisions in an 'epigenetic drift' process associated with aging. And so epigenetic factors may play an important role in patterning the body plan during normal development especially when they become older. Therefore the real causes for monozygotic twin discordance for common diseases are yet to established [3]. Petronis propose a modification of a paragigmatic equation: $P$ (phenotype $)=G$ (genes) $+E$ (environment) to $P=G+E+$ EpiG (epigenetics) [22].

van Rhijn et al. [25] described that differences in scoliosis in the development, progression of the scoliosis and age at detection (juvenile vs. adolescent) may have been caused by environmental influences. Other non-genetic evidence that environmental factors play a role in the expression of idiopathic scoliosis was raised by Nachemson and Mc Master [17-19].

Ponseti and Friedman [23] suggest that curve type is genetically determined and that curve types are well established shortly after the detection of the scoliosis and do not change throughout its course. van Rhijn et al. [26] noted that only half of the twin pairs showed a difference in lateral Cobb angles of less then $10^{\circ}$. These findings suggest that curve severity may be affected by environment. Whereas Kesling and Reinker [13] compared 20 sets of monozygotic twins to 16 sets of dizygotic twins, the correlation coefficient for the lateral Cobb angle in monozygotic twins was 0.74 ; in dizygotic twins it was 0.4. Inoue et al. [11] concluded that there was a genetic factor in curve severity because in 8 of 12 monozygotic twin pairs the difference between lateral Cobb angles was less than $10^{\circ}$. Although 6 of 12 pairs showed discordant curve patterns. One can wonder that curve type is not mainly influenced by genetic factors.

Riseborough and Wynne-Davies[27] considered that curve severity depends on a number of factors, such as the age of development, the speed of progression and the efficacy of treatment. If a strong genetic factor exists for curve severity, scoliosis may be less influenced by conservative treatment. While several authors conclude that brace therapy can stop the progression of the scoliosis and alter the natural history of idiopathic scoliosis, so it can suggest that environmental factors can influence curve severity $[2,5,16,20$, $25,28]$.

Nowadays there is a controversy over brace treatment. Several studies have questioned the effectiveness of bracing. Goldberg et al. [10] reported an untreated series of 153 patients of which $28 \%$ had undergone surgery. Karol [12] concluded that because of the assumed stiffness and more lack of compliance among boys, bracing of boys with adolescent idiopathic scoliosis is questionable. Nonetheless, Yrjönen et al. [35] suggested that brace treatment in adolescent idiopathic scoliosis might be recommended in both genders. Also Ugwonali et al. [30] reported that brace wearing did not decrease the quality of life of adolescents. Despite the controversy over brace treatment there is evidence that brace treatment can alter the natural history of idiopathic scoliosis [2, 5, 16, 20, 25, 28]. Nonetheless Negrini et al. highlighted the lack of scientific evidence of studies on the conservative management of scoliosis by physical therapy, intensive rehabilitation and brace treatment (a grade of evidence $\mathrm{c}$ or lower) [14, 21, 33]. Therefore Weiss et al. [31] appointed guidelines for conservative management of scoliosis with a prognostic risk estimation of Lonstein and Carlson [15].

The age for detection of idiopathic scoliosis is divided into three age groups: Infantile, juvenile, and adolescent [29]. A literature search in Pubmed (NML) yielded no articles about different ages for detection of idiopathic scoliosis in monozygotic twins. Our monozygotic twin pair suggests that there is a different age at detection of their scoliosis.

Monozygotic twin studies are necessary to understand why there are differences in curve patterns, age of detection and curve severity of idiopathic scoliosis. It still remains uncertain if epigenetic modification is the basis for these differences. It may be influenced by environmental factors. We would like to emphasize that environmental factors influence idiopathic scoliosis which is a dynamic process and not a fixed deformity [24].

\section{References}

1. Carr AJ (1990) Adolescent idiopathic scoliosis in identical twins. J Bone Joint Surg Br 72(6):621-625

2. Carr WA, Moe JH, Winter RB et al (1980) Treatment of idiopathic scoliosis in the Milwaukee brace. J Bone Joint Surg Am 62:599-612

3. Cavalli G (2006) Chromatin and epigenetics in development: blending cellular memory with cell fate plasticity. Development 133(11):2089-2094

4. De George FV, Fisher RL (1967) Idiopathic scoliosis: genetic and environmental aspects. J Med Genet 4(4):251-257

5. Emans JB, Kaelin A, Bancel P et al (1986) The Boston bracing system for idiopathic scoliosis. Follow-up results in 295 patients. Spine 11:792-801

6. Emery AE (1986) Methodology in medical genetics: an introduction to statistical methods. 2nd edn. Churchill Livingstone, Edinburgh 
7. Fisher RL, De George RL (1967) A twin study of idiopathic scoliosis. Clin Orthop 55:117-126

8. Fraga MF, Ballestar E, Paz MF et al (2005) Epigenetic differences arise during the lifetime of monozygoyic twins. Proc Natl Acad Sci USA 102(30):10604-10609

9. Galton F (1875) The history of twins, as a criterion of the relative power of nature and nurture. Pop Sci Mon 8:345

10. Goldberg CJ, Moore DP, Fogarty EE et al (2001) Adolescent idiopathic scoliosis: the effect of brace treatment and the incidence of surgery. Spine 26:42-47

11. Inoue M, Minami S, Kitahara H et al (1998) Idiopathic scoliosis in twins studied by DNA finger printing: the incidence and type scoliosis. J Bone Joint Surg Br 80B:212-217

12. Karol LA (2001) Effectiveness of bracing in male patients with idiopathic scoliosis. Spine 26:2001-2005

13. Kesling KL, Reinker KA (1997) Scoliosis in twins: a metaanalysis of the literature and report of six cases. Spine 22:2009-2014; discussion 15

14. Limb D, Hay SM (2007) Introduction, using evidence-based medicine in orthopaedic surgery. In: Limb D, Hay SM (eds) The evidence for orthopaedoc surgery. tfm Publishing Ltd, Shrewsbury, pp 1-4

15. Lonstein JE, Carlson JM (1984) The prediction of curve progression in untreated idiopathic scoliosis during growth. $\mathbf{J}$ Bone Joint Surg 66A:1061-1071

16. Lonstein JE, Winter RB (1994) The Milwaukee brace for the treatment of adolescent idiopathic scoliosis. A review of one thousand and twenty patients. J Bone Joint Surg Am 76:1207-21

17. McMaster ME, Lee AJ, Burwell RG (2005) Physical activities of patients with adolescent idiopathic scoliosis (AIS) compared with a control group: implications for etiology and possible prevention J. Bone Joint Surg Br 88(Suppl 2):225

18. McMaster ME, Lee AJ, Burwell RG (2006) Indoor heated swimming pools: the vulnerability of some infants to develop spinal asymmetries years later. Research into Spinal Deformities 5, Health Technology and Informatics 123:151-155

19. Nachemson AL (2004) Future research in scoliosis: possible neuromuscular causes. In: Jacobs RR (ed) Pathogenesis of Idiopathic Scoliosis, Proceedings of an international conference. Scoliosis Research Society, Chicago, pp 143-152

20. Nachemson AL, Peterson LE (1995) Effectiveness of treatment with a brace in girls who have adolescent idiopathic scoliosis. A prospective, controlled study based on data from the Brace Study of the Scoliosis Research Society. J Bone Joint Surg Am 77:815-22
21. Negrini S, Aulisa L, Ferraro C, Fraschini P, Maseiro S, Simonazzi P, Tedeschi C, Venturin A (2005) Italian guidelines on rehabilitation treatment of adolescents with scoliosis or other spinal deformities. Eura Medicophys 41:183-201

22. Petronis A (2006) Epigenetics and twins: three variations on the theme. Trends Genet 22(7):347-50

23. Ponseti IV, Friedman B (1950) Prognosis in idiopathic scoliosis. J Bone Joint Surg 32:381-96

24. van Rhijn LW (2005) Classification systems. Thesis: Dynamics and relationships idiopathic scoliosis Maastricht

25. van Rhijn LW, Jansen EJP, Plasmans CMT et al (2001) Changing curve pattern in infantile idiopathic scoliosis. Family report with a follow-up of 15 years. Spine 26:373-6

26. van Rhijn LW, Jansen EJP, Plasmans CMT et al (2001) Curve characteristics in monozygotic twins with adolescent idiopathic scoliosis: 3 twin pairs and a review of the literature. Acta Orthop Scand 72(6):621-5

27. Riseborough EJ, Wynne-Davies R (1973) A genetic survey of idiopathic scoliosis in Boston, Massachusetts. J Bone Joint Surg Am 55-A:974-82

28. Rowe DE, Bernstein SM, Riddick MF et al (1997) A metaanalysis of the efficacy of non-operative treatments for idiopathic scoliosis. J Bone Joint Surg Am 79:664-74

29. September 2000 In depth review of scoliosis: idiopathic scoliosis. Available at: http://www.srs.org/patients/review

30. Ugwonali OF, Lomas G, Choe JC et al (2004) Effect of bracing on the quality of life of adolescents with idiopathic scoliosis. Spine J 4:254-60

31. Weiss H-R, Negrini S, Rigo M, Kotwicki T, Hawes MC, Grivas TB, Maruyama T, Landauer F (2006) Indications for conservative management of scoliosis (guidelines). scoliosis 1:5 DOI:10.1186/1748-7161-1-5

32. Wong AHC, Gottesman II, Petronis A (2005) Phenotypic differences in genetically identical organisms: the epigenetic perspective. Hum Mol Genet 14:11-18

33. Wright JG, Swiontkowski MF, Heckman JD (2003) Introducing levels of evidence to the Journal. J Bone Joint Surg Am 85A(1):1-3

34. Wynne-Davies R (1968) Familial (idiopathic) scoliosis. A family survey. J Bone Joint Surg Br 50(1):24-30

35. Yrjönen T, Ylikoski M, Schlenzka D et al (2006) Results of brace treatment of adolescent idiopathic scoliosis in boys compared with girls: a retrospective study of 102 patients treated with the Boston brace. Eur Spine J (Epub ahead of print) 